\title{
The Case Analysis of Disney with Scarlett Johansson Litigation
}

\author{
Xiaoyuan $\mathrm{Ye}^{*}$ \\ Green River College, Washington, United States \\ *Corresponding author: guanghua.ren@gecacademy.cn
}

\begin{abstract}
This article will discuss the lawsuit Scarlett Johansson filed against Disney over the streaming trend. This paper will precisely analyze the case to understand their right to be opposed and how they reacted throughout the lawsuit. In addition, the impact of this action on the film business is significant and is included in this article. Background on the lawsuit. According to Disney's response to the lawsuit, Johnson received a $\$ 20$ million advance salary for appearing in the film, but her complaint states that making the film available through Disney plus increased the value of the streaming service but decreased office revenue.
\end{abstract}

Keywords: Case Analysis, Disney, Lawsuit, Scarlett Johansson.

\section{Introduction}

The Marvel star Scarlett Johansson is suing Walt Disney. On July 29, Johansson filed a lawsuit in Los Angeles Superior Court, claiming the company breached its contract when it released the movie "Black Widow" on its streaming service Disney plus while it was in theaters. Johnson claims she agreed to Disney Marvel Entertainment's guarantee of exclusive theatrical release of her solo film, and that her salary was based on box office performance. Johnson tried to negotiate with Marvel, which is owned by Disney, but neither of them responded to her. Disney called the lawsuit "particularly sad and distressing" because it ignores the horrific global impact of the Covid-19 pandemic, Disney's full compliance with Ms. Johnson's contract, and the release of "Black Widow" on Disney plus through Premier Access, which significantly enhances her ability to earn more than the $\$ 20$ million she has received to date. additional compensation beyond the $\$ 20$ million received to date. "Disney is known for releasing movies like 'Black Widow' directly to Disney plus to increase subscribers and thereby boost the company's stock price - and it hides behind Covid-19 as an excuse to do so," said John Berlinski (John Berlinski), who represents Johnson's Kasowitz-Benson Torres, told CNBC.

BATNA stands for Best Alternative to Negotiated Agreement Abbreviation. This refers to the act of negotiating a failed, unreachable agreement. BATNA is often useful in negotiation strategy and should always be considered before negotiations begin. It is not wise to negotiate without knowing your BATNA. The value of knowing the best alternative to a negotiated agreement is that the BATNA can provide an alternative if negotiations fail, it can also provide negotiating power, and it determines your booking point (the worst price you are willing to accept). Therefore, BATNA's first option was for Disney to take the initiative to soften up and pay Scarlett a sum of money to continue to let Scarlett play the Black Widow. Meet Scarlett who came up with a

Manuscript received October 26, 2021.

X. WY. Ye is studying in Green River College, 98031, United States (e-mail: Ye.Xiaoyuan@Student.greenriver.edu).

new way to calculate the box office. But recently, Disney has had to consider the environmental impact of the new coronavirus. If the next time there is a Black Widow sequel,

Disney will have to pay, including whether it will recoup its capital. The second BATNA option is for the two parties to separate and never work together again. This means Scarlett will never appear in a Marvel or even Disney movie again. This may not be good for Disney's reputation. Including post-production, Disney will have to find a new "Black Widow", but this does not require compensation. So relatively speaking, the second, Disney's financial loss is relatively small. 
It is believed that the strategy Scarlett used in her lawsuit was "leverage". This means that she can save herself through public opinion. In negotiations, leverage is the power that one party must have to influence the other party to get closer to its negotiating position. A party's influence depends on its ability to provide benefits or increase costs to the other party. Those with high leverage can sometimes overcome weak negotiating skills, while those with low leverage are less likely to succeed even with strong negotiating skills. Leverage can be measured qualitatively as the loss suffered by one party as a result of failure to reach an agreement. Usually, the party or group that needs an agreement mostly has the least leverage. Otherwise, the party or group willing to leave (if possible) has the most leverage. First, Scarlett has a long history of playing the Black Widow. In the public's potential impression, she is the Black Widow. Therefore, it is hard for the audience to accept her sudden change. Second is the other celebrities signed by Disney. Since she is the first one to show a big move, other celebrities in the entertainment industry may secretly and actively help her because they are also afraid of damaging their own interests. After all, there are a lot of movies streaming nowadays, so this case has brought an irresistible impact on the movie business.

\section{2. the case}

\subsection{Introduction to the operating status of Disney}

The Walt Disney Company, one of the world's largest entertainment and media companies, is the world's most respected entertainment and media company, ranking second among global media companies in terms of revenue, behind Time Warner [1]. Disney owns the world's number one entertainment and film brand Disney, film, and television entertainment (one of the largest film distributors in the United States), theme parks and resorts (the world's largest theme park group), media networks (owns ABC, one of the three largest broadcasters in the United States, sports brand ESPN), consumer products (the world's largest children's consumer brands, the world's largest children's The Disney Company was founded in 1923. Founded in 1923 as the Disney Brothers Cartoon Studio by the brothers Walt Disney and Roy Disney, Disney is now one of the world's largest entertainment companies, continually striving to provide the most special entertainment experiences for people and has remained true to the company's tradition of excellence in the constant pursuit of quality and innovation. The Walt Disney Company's film distribution brands include Walt Disney Pictures, Touchstone Pictures, Hollywood Pictures, Miramax Films, 20th Century Studios, Dimension Films, Pixar Animation Studios, and Marvel Studios, LLC [1]. The three brands, Walt Disney, Touchstone, and Hollywood, have had more than a dozen collaborations with gold medalist filmmaker Jerry Bruckheimer. Disney has a distribution partnership with Ghibli.

Disney's overall development strategy is to take IP creation as the core and starting point to form a closed-loop ecological industry chain of "IP + media + theme park + content + technology" [2]. For cultural enterprises, the core asset is quality content, i.e., IP, and IP creation is the source and core of Disney's entire industry chain. Disney not only has a large stock of IP, and is still creating new IP, whether Mickey, Donald Duck or Mad Animal City rabbit officer Judy, Nick the fox, creating countless classic images. Disney's own strong, continuous IP creation, promotion capabilities, is the same industry competitors do not have, is also its most important core competitiveness [2]. For a single business theme park business, Disney's Road cannot be copied. At present, Disney has formed a relatively complete industry chain around IP resources, that is, from the formation of animation, film, and television IP to the promotion and marketing of IP images, to the launch of theme parkrelated products, and then to the development of derivatives. In addition, the brand licensing around IP also creates more revenue channels for Disney, becoming a "protective wall" for its sustainable development, making its industrial chain tenser. In watches, accessories, women's clothing, bags, home furnishings, plush toys, electronic products, and other consumer segments, there is often Disney's classic images, covering almost every aspect of people's clothing, food, housing, and transportation. 
The media network business, represented by ESPN and ABC, accounts for the largest part of the revenue of the entire Disney Group, with a proportion of about 40\%. 1996 Disney bought ABC and its affiliated television networks, ESPN sports channels, and other businesses for \$19 billion, and in 2001 spent $\$ 5.2$ billion to acquire FOX Family Channel for cash plus debt, thus building up its in 2001, it acquired FOX Family Channel for $\$ 5.2$ billion in cash and debt, thus establishing the main framework of its media network business segment (Show in Figure 1) [3].

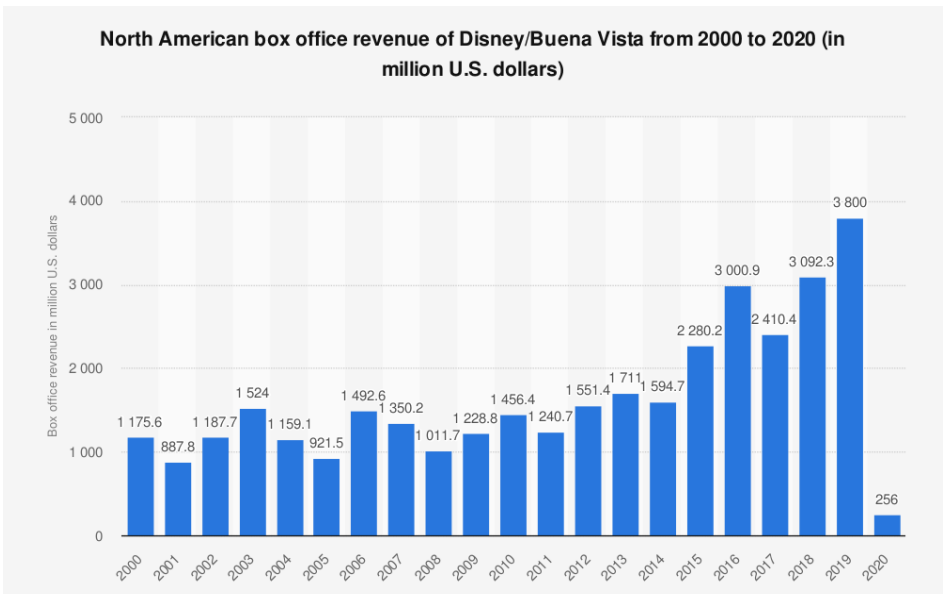

Fig 1. North American box office revenue of Disney from 2000 to 2020 (in million U.S. dollars).

To date, the Media Networks segment includes broadcast and cable networks, television content production and operations, television distribution, domestic television stations, and broadcast network stations. Since 2012, the media network segment's revenue, especially net profit growth, has been declining and slowing down, with both the FY16 and FY17 interim reports showing negative operating profit growth, mainly due to two factors: First, the number of ESPN TV subscribers continues to decline. more than one-third. Subscription fees are extremely high, reaching $\$ 7.50$ per month for a subscription, but viewers still willingly pay for it because of the wealth of event resources at their disposal. However, with the impact of online streaming platforms, ESPN has been losing paying subscribers at a rate of 2-3 million almost every year since 2011 until the end of the first quarter of the fiscal year 2017, when ESPN's subscriber base had fallen from a high of 100 million paying viewers in 2011 to 88 million (Show in Figure 2) [4].

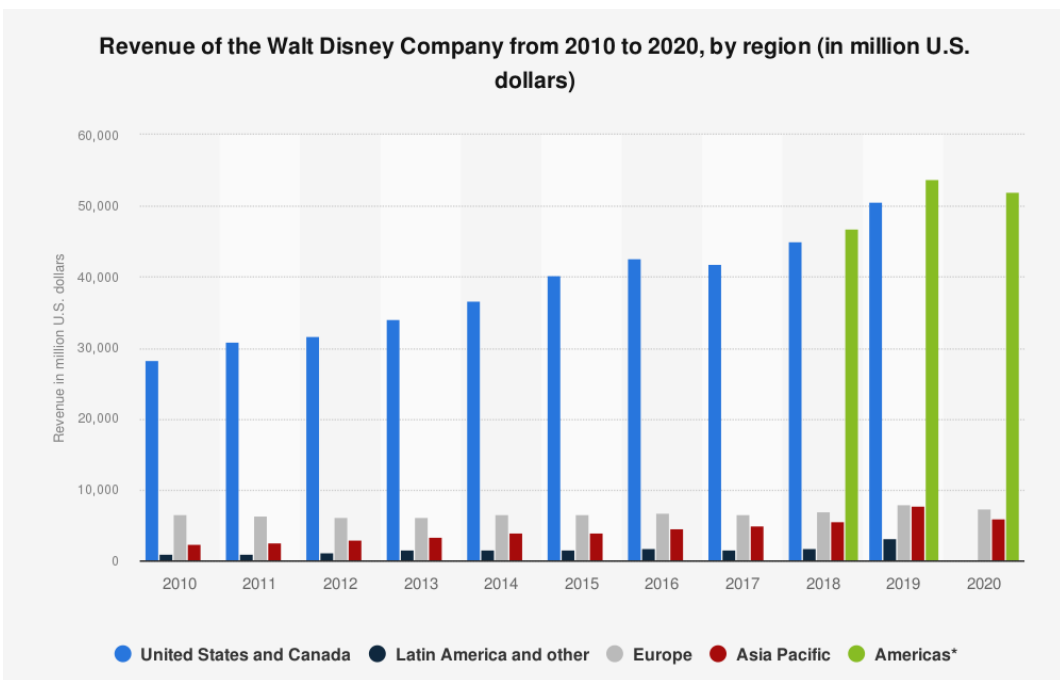

Fig. 2. Revenue of the Walt Disney Company from 2010 to 2020, by region (in million U.S. dollars). 
And from the perspective of industry development, network streaming will become stronger and stronger, and this downward trend is difficult to be fundamentally reversed. Second, ESPN pays too much for event rights. ESPN cooperates with sports leagues including the four major sports in the United States (NBA, NFL, NHL and MLB) and so on, but in order to win the bid in the fierce competition with TNT and NBC, the contract price quoted in recent years is getting higher and higher, and the price of event rights to be borne is more than $\$ 8$ billion per year, even if the number of ESPN users does not decline in 2017, the user subscription fee received is about Only $\$ 7.6$ billion, cannot even cover the cost of copyright, copyright has turned from an advantage into a liability. The company has tried some improvement methods, such as the launch of OTT (over-the-top) services, independent streaming subscription services (users can choose their own specific games to subscribe to) but has not yet seen significant results.

Although this information is from previous years, it can also be used to analyze the opportunities, risks, and solutions for the industries in which the Disney Company operates. First, there are two points in terms of market opportunities for the Disney Company. The first is that Disney's television industry is relatively weak, as Disney's main focus is the amusement park project, the amusement park project is also the most profitable project for Disney. There is a large market gap in the television industry to be filled. The second point is that the American Broadcasting Company (ABC) is in short supply of programs and stagnant. Disney can put their commercials or cartoons and movies to ABC. Although Disney has these seemingly very good opportunities, there are risks involved. The first is Disney's lack of experience in operating in the television industry. The second is that if Disney animation is pushed to the television market, it may reduce the box office revenue of theaters to some extent. However, Disney has a very big advantage in the TV industry, firstly, the brand value of Disney, secondly, the celebrity effect of Walt Disney, and finally, Disney has a large inventory of films. I believe that these advantages are enough to make Disney in the television industry to establish a firm foothold and have very high ratings.

\subsection{Scarlett Johansson Introduction}

Scarlett Johansson, born in 1984, is one of the most promising teenage stars in Hollywood today. Scarlett Johansson was born in New York City to her brother, a dragon, and child. She has been acting professionally since she was eight years old, and her interest in acting was evident at the age of three [5]. Growing up Scarlett enrolled in an acting school that specialized in training young actors, and soon after graduation, she was on the small theater stage. Her partner for her stage debut was Ethan Hawke. In 1994, Scarlett starred in her first film, North, and in 1996, Scarlett starred in Manny and Lo, which was nominated for an Independent Spirit Award for Best Actress and won Best Actress at the Venice Film Festival and the BAFTA Awards in 2003 for Lost in Tokyo. In 2007, Scarlett starred in "The Nanny Diaries" and in August 2009, Scarlett was named one of the top ten sexiest actresses in the world by the British fashion magazine Glamour. 2011, Scarlett starred in "The Avengers" and in November 2013, Scarlett starred in "Under the Skin". Scarlett was nominated for Best Actress at the 16th British Independent Film Awards for Under the Skin and won the Best Actress Award at the Rome Film Festival for Her, becoming the first actress in the history of the festival to win for her voice [6].

\section{Review and Analysis of the Case}

\subsection{Review to the Disney Company vs. Scarlett Litigation}

At the beginning of August, the news of Scarlett Johansson suing Disney for "Black Widow" became the focus of media attention. Initially, it was scheduled to receive extra revenue and film pay through the theater contract, but due to the epidemic, Disney took the form of simultaneous release through our OTT (Disney plus) online and offline, however, Scarlett Johansson's side protested this [7]. Because of the simultaneous release through OTT, Scarlett Johansson will get a decrease in the earnings of the film. As a result, Scarlett Johansson's side filed a lawsuit against Disney, claiming a 
loss of \$50 million [7]. Disney had already paid the extra revenue, and the original contract called for a "wide theatrical release," which did not mean a theatrical release only. But Johnson explained that it was a "cinema-only" release, refuting Disney's claim. With the two sides on opposite sides of the issue, actors and fans saw this as an act of "corporate hegemony" by Disney, seemingly siding with Scarlett Johansson. In fact, from Johansson's point of view, it was enough to make her feel wrong, so her claim was justified. But from the perspective of the media industry in Western Europe, including the United States, the lawsuit is more or less complicated. The majority believes that in the context of the lawsuit, the nascent industry of mobile media services became the dominant market due to the outbreak of the epidemic, so the court will further refer to that. From this point of view, the issue is very much against the preservation of the actors' rights. Therefore, in the United States, the majority opinion is that the lawsuit is unfavorable to Scarlett Johansson and will eventually accept the agreement case proposed by Disney. This means that the entertainment industry like Hollywood will not focus on the extra earnings of the stars and therefore the content production structure will change and from this point of view the lawsuit is worth watching.

First of all, "Black Widow" didn't do well at the streaming box office. According to an article in deadline (English: deadline) on July 29, "Black Widow" posted first-week box office earnings of \$60 million at Disney plus. Although it seems to be a huge gain, $15 \%$ of it will be deducted as a processing fee from platforms such as Amazon fire stick and Apple TV plus that supports the Disney plus service [8]. In this way, the remaining amount is only $\$ 51$ million, which is the main source of revenue. However, the media outlet said that there are many additional expenses in the remaining amount, so Disney will not actually gain a lot of revenue. This is obviously much less compared to the revenue obtained through the cinema. One of the biggest problems is the flow of illegal pirated copies overseas. In China, the largest market for Disney and Marvel, "Black Widow" suffered losses of up to \$200 million [8]. There are too many pirated copies circulating on Chinese websites, and the movie is publicly available at the same time through mobile services, so it is easy to leak out.

Secondly, the era of "actor-dependence" for studios is now over. This means that even if Scarlett Johansson's side wins her case, she will not get a real cut. As I mentioned before, the influence of Hollywood stars is less than it used to be as the influence of mobile media companies grows. Disney will use the lawsuit as an opportunity to try to move away from its reliance on the star system as long as it pays Scarlett Johansson for her films.

\subsection{Analysis of the Litigation between Disney Company and Scarlett}

This situation is actually like you are a painter, the original partner promised to give you a painting exhibition, but the result ended up making it a web exhibition, resulting in your expected income reduced by a lot. If it was originally earning $\$ 10,000$, leaving $\$ 5,000$, you might think nothing of it. But Scarlett Johansson's salary has reached the level of ten million dollars and can enjoy box office dividends. A movie like "Black Widow" is calculated at the global box office in excess of $\$ 100$ million. According to the Wall Street Journal, a person familiar with the matter revealed that Disney sent "Black Widow" to a streaming synchronized theatrical premiere, which cost Scarlett Johansson $\$ 50$ million in potential earnings for nothing.

The suit is especially sad and distressing in its callous disregard for the horrific and prolonged global effects of the COVID-19 pandemic [9]. "Predictably, Disney is now trying to hide its misconduct in confidential arbitration," Johnson's attorney, John Berlinski, told USA Today in a statement. "Why is Disney so afraid to file a lawsuit in the public square?" Following Johnson's complaint, Disney issued a statement calling the lawsuit "particularly sad and painful because it ignores the horrific and long-term global impact of the COVID-19 pandemic" [9]. Bryan Lourd, the co-chair of Creative Artists Agency and Johnson's agent, issued a response to Disney, saying the company "shamelessly and wrongly accuses Ms. Johnson of being insensitive to the global COVID epidemic. The response was "a direct attack on her character" [10].

With the rise of the mobile industry, the original model of sharing the benefits of the cultural information market has changed. Previously, many organizations used box office revenues as a 
criterion for ticket sales, but now the number of subscribers to mobile platforms has become the new criterion. Regrettably, platform production companies and actors do not share the benefits of this. This indicates that the influence of the stars has significantly diminished. There are many reasons for the waning influence of stars, but the most noteworthy reason cited by the media is that production companies are now more concerned about the ownership of the highly popular film and TV IPs like Star Wars than the stars. no popular series representing each platform, such as Netflix's Stranger Things, Disney plus's The Mandalorian, Amazon prime's The Boy, have the worthy attention of heavyweight star actors (of course their value has increased with the success of the series). Ultimately there are distinctive stories and themes of the productions that appeal to the OTT platform audience. Even in the recently produced series of The Lord of the Rings on Amazon prime, there are almost no stars as common as they are. Disney plus has 140 million subscribers in just a year and a half since it began service and ranks third online behind Netflix and Amazon. Star Wars, Marvel, and others have dominated the movie industry using huge intellectual properties, and actors want to be part of the franchise anyway for a stable career. The media says the emergence of this new order will also have an impact on this lawsuit against Scarlett Johansson, which is expected to have the same outcome as top star Taylor Swift. Taylor Swift recently reached an agreement with the world music platform Sportify before the lawsuit.

\section{Limitation}

While both sides are at loggerheads, several industry insiders claim that the party responsible for the incident is actually Disney's current CEO Bob Chapek. They claim that if Bob Iger (the former CEO of Disney) was still in office, things would not have come to this. Bob Chapek made a mistake, and he didn't expect to mess things up. He was not in charge of signing contracts with artists and did not have much experience dealing with them. Many people believe that the strategy of Disney CEOs today is to prioritize streaming and stock prices and take a back seat to relationships with artists. The box office success of Marvel movies in theaters can't directly lift the stock price, but an increase in Disney subscriptions can. Disney is reluctant to give Scarlett Johansson a potential $\$ 50$ million dividend, feeling that stock market performance is more important.

Although in the eyes of the masses, Disney is very important for Scarlett, but there are still people who think that Disney is not much for Scarlett. Originally Black Widow was full of male gaze, and many interviews also implicitly had hosts delivering bias-filled questions. Although Black Widow let Scarlett has a better visibility, but the live-action film is only now out, but also for this reason on the lawsuit. Not only that, but Scarlett has also been in the shadow of Black Widow, everyone mentioned her are talking about the Black Widow. Now Scarlett has become a starlet top in Hollywood, for Disney this kind of company that will only come out with some popcorn movies, Scarlett does not need to go begging for cooperation.

\section{Conclusion}

At the end of July, Scarlett filed a lawsuit against Disney for intentionally inducing Marvel Studios to breach the agreement without any justification in order to prevent Ms. Johnson from completing the revenue she had negotiated with Marvel Studios. To put it simply, Scarlett's side argued that by allowing "Black Widow" to be released in both Disney plus and theaters, it affected the film's box office revenues. The majority of her income, however, is tied to box office revenue. Disney, for its part, felt at the time that Scarlett was ignoring the impact of the epidemic while filing a lawsuit. But this is indeed a good thing for the streamer. That year, streaming platform Netflix released a total of 80 original movies, an average of one every four days. This fast-food output has been a descending blow to traditional Hollywood studios, bringing a lot of competitive pressure. At the same time, Apple, Amazon, YouTube, and other Internet technology giants continued to share the movie market, making this showdown between the old and new forces thoroughly into the heat. The lack of original content 
and scale ecology makes the competition between streaming media and traditional Hollywood studios, often fall into the disadvantage. To turn the situation around, streamers have acquired various original rights on one side, for example, Amazon spent \$250 million in 2017 to acquire the rights to The Lord of the Rings. On the other hand, it has started a separate business to step up the production of its own original content. As a result, streaming media, backed by capital, has gained a stage victory. And in 2019, Disney officially launched its own streaming media platform Disney plus.

In just over 1 year, the global paid subscription users exceeded 100 million. And "Black Widow" by the impact of the epidemic, the global box office income is far less than expected, but on the contrary, after the launch of Disney plus, income up to $\$ 60$ million, making Disney very satisfied.

After two months of this case, the lawsuit between the two sides finally came to fruition. Recently, according to THR and many other authoritative media reports, Disney reached a settlement on the lawsuit filed by Scarlett about "Black Widow" release breach of contract [11]. Disney Pictures Chairman Alan Bergman also released his own statement through the media, in which he expressed his gratitude for the settlement. "I am delighted that we were able to reach a mutual agreement with Scarlett Johansson on 'Black Widow'. We thank her for her contributions to the Marvel Cinematic Universe and look forward to working together on a number of upcoming projects, including Disney’s Tower of Terror" [12].

\section{Reference}

[1] Encyclopædia Britannica, inc. (n.d.). Disney Company. Encyclopædia Britannica. Retrieved October 24, 2021, information from https://www.britannica.com/topic/Disney-Company.

[2] SS Rana \& Co. (2020, April 2). Role of IP in the growth of Disney. Lexology. Retrieved October 24, 2021, information from https://www.lexology.com/library/detail.aspx?g=e31b49ef-ca97-43e7-84817df54979cf4d.

[3] Navarro, J. G. (2021, August 12). North American box office revenue of Disney/Buena Vista 2020. Statista. Retrieved October 24, 2021, information from https://www.statista.com/statistics/187329/boxoffice-revenue-of-disney-in-north-america-since-2000/.

[4] Stoll, J. (2021, January 13). Walt Disney revenue by Region. Statista. Retrieved October 24, 2021, information from https://www.statista.com/statistics/193263/revenue-of-the-walt-disney-company-indifferent-regions/.

[5] Biography. (2021, August 18). Scarlett Johansson. Biography.com. Retrieved October 24, 2021, information from

https://www.biography.com/actor/scarlettjohansson\#: :text=Scarlett\%20Johansson\%20was\%20born\%20in,critical\%20acclaim\%20at\%20age\%20 13.\&text=Exploring\%20other\%20artistic\%20avenues\%2C\%20Johansson,she $\% 20$ made $\% 20$ her\%20Bro adway\%20debut.

[6] Wikimedia Foundation. (2021, October 24). Scarlett Johansson. Wikipedia. Retrieved October 24, 2021, information from https://en.wikipedia.org/wiki/Scarlett_Johansson.

[7] Johnson, T., \& D'Alessandro, A. (2021, July 29). Disney strikes back over Scarlett Johansson's 'Black widow' lawsuit, reveals her \$20 million payday - update. Deadline. Retrieved October 24, 2021, information from https://deadline.com/2021/07/scarlett-johansson-walt-disney-co-black-widow-lawsuit$1234802440 /$.

[8] Nyberg, S. (2021, September 9). Scarlett Johansson vs disney: Lawsuit fully explained. Home -. Retrieved October 24, 2021, information from https://thedisinsider.com/2021/09/09/scarlett-johansson-vs-disneylawsuit-fully-explained/.

[9] Agustin, F. (2021, August 21). Disney files motion to move 'Black widow' suit to closed-door arbitration, calling Scarlett Johansson's attempts to publicize it 'gamesmanship'. Business Insider. Retrieved October 24, 2021, information from https://www.businessinsider.com/disney-arbitration-scarlett-johanssonlawsuit-2021-8.

[10] Patten, D. (2021, September 30). Disney \& Scarlett Johansson Resolve Bitter 'Black Widow' profits lawsuit; big \$\$ win for Oscar nominee. Deadline. Retrieved October 24, 2021, information from https://deadline.com/2021/09/disney-black-widow-lawsuit-scarlett-johansson-rsettlement-1234847437/. 
[11] Barnes, B. (2021, September 30). Scarlett Johansson and Disney Settle Suit Over 'black widow' pay. The New York Times. Retrieved October 24, 2021, information from https://www.nytimes.com/2021/09/30/business/scarlett-johansson-disney-black-widow.html.

[12] Masters, K. (2021, October 7). Scarlett Johansson, Disney Settle Explosive 'black widow' lawsuit. The Hollywood Reporter. Retrieved October 24, 2021, information from https://www.hollywoodreporter.com/business/business-news/scarlett-johansson-disney-settle-blackwidow-lawsuit-1235022598/. 